Revista Iberoamericana. Vol. LXIV, Núms. 182-183, Enero-Junio 1998; 299-311

\title{
LA SUJETIVIDAD FEMENINA EN LA METAFICCIÓN FEMINISTA LATINOAMERICANA
}

\author{
POR \\ LAURA J. BEARD \\ Texas Tech University-Lubbock
}

En los últimos años, hemos visto que varias teorías del posmodernismo y del feminismo comparten un deseo de romper con las distinciones tradicionales de varias oposiciones binarias: "el arte" y "la vida", lo masculino y lo femenino, la alta cultura y la cultura popular, lo central y lo marginal. Desafían el dominante concepto liberal de la sujetividad, con su creencia en un ser unido y en una naturaleza humana universal. ${ }^{\prime}$ En el posmodernismo el sujeto tradicional ha cedido paso al sujeto "descentrado" o a la idea de que no hay sujeto, sólo un sistema de estructuras lingüísticas, una construcción textual, un juego de diferencias en el sentido de Jacques Derrida. Muchas teorías feministas reconocen la sujetividad como una posicionalidad relativa siempre cambiable. Críticas como Teresa de Lauretis y Judith Butler acuden a la teoría de la sexualidad de Michel Foucault para proponer una reconceptualización del género sexual como algo que no es una propiedad de cuerpos, ni algo presente al nacimiento, sino una construcción social, el producto de tecnologías sociales, de discursos institucionalizados y de prácticas epistemológicas y críticas. Esta reconceptualización desata el género sexual de la oposición binaria de hembra y varón y admite el imaginar de construcciones alternativas del género y de la sujetividad. Para citar a de Lauretis, hay

a subject constituted in gender, to be sure, though not by sexual difference alone, but rather across languages and cultural representations; a subject engendered in the experience of race and class, as well as sexual, relations; a subject, therefore, not unified but rather multiple, and not so much divided as contradicted (2).

Es este concepto de la sujetividad que quiero examinar en la ficción de Helena Parente Cunha y Luisa Futoransky, cuyas obras narrativas yo designo feministas.

Al designarlas feministas, empleo la definición que utiliza Rachel Blau DuPlessis en su libro, Writing Beyond the Ending: Narrative Strategies of Twentieth-Century

\footnotetext{
' Utilizo la palabra sujetividad en la misma acepción dada al vocablo sujeto, diferente por tanto del concepto de subjetividad.
} 
Women Writers. DuPlessis examina las estrategias de varias escritoras inglesas y norteamericanas para mostrar cómo separan la narración de las estructuras convencionales que la ficción y la conciencia mantienen sobre las mujeres. DuPlessis afirma:

any female cultural practice that makes the "meaning production process" itself "the site of struggle" may be considered feminist.[...] authors are "feminist" because they construct a variety of oppositional strategies to the depiction of gender institutions in narrative (34).

DuPlessis nos recuerda que las obras literarias siempre expresan una ideología, y por eso, ella examina las estrategias narrativas de escritoras contemporáneas para ver cómo cambian la ficción para que haga declaraciones diferentes -o declaraciones de diferencia - sobre el género sexual y sus instituciones. El libro de DuPlessis se basa en la proposición de que las estructuras y los sujetos narrativos son como los aparatos funcionales de la ideología, lo que ella define como un sistema de representaciones a través del cual imaginamos al mundo como es (3). Las convenciones literarias tramas, personajes, secuencias narrativas- se usan no sólo para representar la experiencia sino también para interpretar esa experiencia. DuPlessis insiste en que ninguna convención es neutra, ni puramente mimética ni estética (2).

Una escritora expresa su disensión con una formación ideológica atacando los elementos de la narración que repiten, sostienen o incorporan los valores y las actitudes en cuestión. DuPlessis explica: "So after breaking the sentence, a rupture with the internalization of the authorities and voices of dominance, the woman writer will ... [break] the sequence" (34). DuPlessis muestra como las escritoras que ella estudia conscientes de que las prácticas sociales relacionadas con el género sexual impregnan las obras narrativas - emplean sus narrativas para hacer comentarios críticos sobre la construcción psicosexual y sociocultural de las mujeres (4). Las escritoras que quiero estudiar en este artículo también emplean estrategias que expresan una disensión crítica de los modelos narrativos dominantes; son escritoras que escriben de manera diferente para engendrar la autoridad de manera diferente. Son escritoras latinoamericanas que caben dentro de la definición de DuPlessis de una escritora feminista: rompen la oración y cortan la secuencia; emplean su metaficción para poner en tela de juicio la sujetividad femenina.

Desde los momentos iniciales de su primera novela, Mulher no espelho (1985), Helena Parente Cunha juega con la idea de la sujetividad, desafiando el concepto autobiográfico tradicional de que el sujeto es único, auto-idéntico, estable. ${ }^{2}$ En esta novela, vemos al sujeto constituido por la experiencia de raza, de clase y de género sexual, el sujeto múltiple y contradictorio descrito por de Lauretis. La protagonista de la novela es una mujer burguesa de cuarenta y cinco años, sin nombre, de Salvador, Bahía. Con un matrimonio fracasado, tiene que definirse de nuevo a sí misma. Decide

\footnotetext{
${ }^{2}$ Para una observación más de cómo Parente Cunha juega con las convenciones autobiográficas, ver mi artículo, "The Mirrored Self".
} 
mirarse frente a unos espejos múltiples, determinada a verse desde todos los ángulos. Piensa contar la historia de su vida, pero no sólo rechaza el género de la autobiografía al proclamar "Não, não vou escrever minhas memórias, nem meu retrato, nem minha biografía" (7), sino que también desafía la idea de sujetividad al presentarse no como sujeto sino como "uma personagem de ficção. Só existo na minha imaginação e na imaginação de quem me lê. E, naturalmente, para a mulher que me escreve" (7). La protagonista reconoce que sólo existe en las palabras del texto; es un sujeto constituido por el lenguaje del texto: "Eu só viverei, se ela me escrever" (16).

En Mulher no espelho, la identidad de la protagonista se constituye en gran parte de la lectura y la escritura. La protagonista recuerda que "[d]esde pequena, sempre gostei muito de ler. ... O meu espaço aberto de liberdade e fantasia. ... Quando leio, corto as correias da sujeição y escapo acima de muitos limites" (67). Se identifica con los personajes de los cuentos de niñas, Rapunzel (94) y Blanca Nieves (77-78). Para la protagonista, escribir es un acto sexual, secreto y transgresor. A los diecisiete años, escribía en un diario secreto que llevaba nombre de chico, "Franky", como la almohada, que era "Johnny". ${ }^{3}$ Con su lenguaje sexual, los convierte en amantes: "A Johnny todas as noites eu entrego o meu botão de rosa que se abre para ele. ... Eu me entrego também para você, meu Franky adorado" (74). Cuando el padre encuentra el diario, se pone furioso; el lenguaje que emplea él _-_"sua imoral, sua perdida, sua desgraçada" (75) _muestra que para este padre autoritario, la escritura y el placer (en particular el autoplacer del acto masturbatorio) son cosas prohibidas para la mujer. ${ }^{4}$

En This Sex Which Is Not One, Luce Irigaray afirma que lo que sigue siendo lo más prohibido para la mujer es cualquier expresión de su propio placer sexual. "For in fact feminine pleasure signifies the greatest threat of all to masculine discourse, represents its most irreducible 'exteriority', or 'exterritoriality"' (157). Irigaray pregunta si la multiplicidad del deseo femenino y del lenguaje femenino tienen que ser entendidos como restos de una sexualidad violada. Plantea que la "rejection, the exclusion of a female imaginary undoubtedly places woman in a position where she can experience herself only fragmentarily as waste or as excess in the Little structured margins of a dominant ideology" (30). A lo largo de la novela, nosotros, como lectores, la vemos fragmentada en tres partes - la protagonista, la "mulher que me escreve" y la autora. La protagonista también sólo puede experimentarse de manera fragmentada: se ve en los espejos, pero ve una multiplicidad de imágenes que se disminuyen, y muchas veces ve una versión del cuerpo sin los pies que han sido comidos por las ratas. Al final de la novela, los espejos se rompen durante una tempestad, fragmentando otra vez el cuerpo de la protagonista.

En "The Power of Discourse", Irigaray afirma que si una mujer quiere expresar su propio placer, se confronta con un camino difícil: "That 'elsewhere' of feminine

\footnotetext{
${ }^{3}$ Claro que los nombres evocan a los amantes famosos de la canción popular, "Frankie and Johnny".

${ }^{4}$ En The Twyborn Affair también vemos la relación con el diario y el acto sexual. En esta novela australiana, se compara escribir en el diario con masturbarse.
} 
pleasure can be found only at the price of crossing back through the mirror that subtends all speculation" (77). Las novelas de Parente Cunha empujan los límites de la narración, del lenguaje, de la pasión y de la imaginación, cruzando por el espejo que subtiende toda especulación para poder entrar en un lugar donde se puede articular un deseo femenino. Parente Cunha celebra la sexualidad femenina y el placer femenino en sus varias formas en Mulher no espelho, una obra metaficcional que amenaza los apuntalamientos de las operaciones lógicas y pone en tela de juicio el sistema de valores del padre burgués autoritario.

La experiencia de clase que marca a la protagonista es la de una familia burguesa, con el padre rey absoluto de la casa, la madre sumisa, el hijo mimado y la hija reprimida. De niña, ella sólo podía jugar con otras niñas, generalmente más jóvenes para que pudiera prolongar la inocencia. Una u otra vez aparece el padre dominante en los recuerdos de la protagonista:

Meu pai, grande demais, anulava todos ao seu redor.[...] Insignificantes éramos todos nós, em volta dele, todo-poderoso, mandando e antimandando, e nós. aos seus pés, submissos, submetidos, subjugados, submergidos, subtraídos (24).

Su padre no le permitía la libertad de expresión ni de ninguna forma de sexualidad; creía que bailar era indecente (46); pensaba que "[m]ulher que se pinta, é mulher da vida" (51) y hasta le quitó la barra de labios de su hija con tanta fuerza que le salió sangre.

Otra parte de la identidad reprimida dentro de la familia burguesa serían los orígenes mulatos. Su padre no le permitía interesarse en el candomblé, "coisa em que branco não se mete. Mas painho, eu não sou branca, eu sou morena. Cale esta boca, menina" (145). En vez de reconocer la posibilidad de la sangre africana, ella tenía que modelarse en la muñeca "de louça, rosto cor-de-rosa, cabelo louro cacheado, [...] os olhos azuis" (10). Es un modelo inalcanzable para la protagonista.

A lo largo de la novela, la protagonista muestra un interés insatisfecho, una fascinación medrosa, para "o menino preto filho da cozinheira da casa do lado [...] [que] sentado no muro, balançando os pés descalços, chupava manga e me sorria" (18). El niño negro no sólo representa lo prohibido ("menina branca não deve se misturar com menino preto" [18]), la libertad (él sube el muro, cruza de un lado al otro), el valor (siempre sale durante las tempestades y se asocia con el dios del trueno), sino también representa la sexualidad, como casi siempre se ve asociado con los mangos maduros, suculentos y jugosos. Un encuentro memorable en el cual el chico se baja el pantalón para mostrarle a la niña "o pequeno sexo duro" le incita a la protagonista a reflexionar en tanto la sexualidad como los orígenes raciales:

Que pretinho bonito. A avó dele foi escrava. E os avós dos meus avós? De onde vem a minha pele morena? Da atenuação dos tons de Nigéria? Do soprar dos ventos quentes da Guiné? Ao som de quais tambores começou a correr o meu sangue? (146) 
En esta cita, como en toda la novela, los tambores y el viento se asocian con Á frica. Como muchas veces el viento trae el olor de los mangos maduros, se asocia otra vez. con la sexualidad.

Además de ser un sujeto constituido por el lenguaje, por la experiencia de raza, de clase y de género sexual, la protagonista de Mulher no espelho ejemplifica el sujeto no unificado sino múltiple, no tanto dividido sino contradictorio definido por de Lauretis. En esta novela brasileña, el sujeto no es unificado sino refractado en tres: la protagonista, la mujer que le escribe y la autora. La protagonista explica las relaciones entre las tres:

Indispensável delinear as fronteiras entre personagem. narrador e autor. A personagem aqui sou eu. O narrador é ela, a mulher que me escreve. O autor não tem nada a ver com a estória. Aliás, a autora. São três entidades que, por força das circunstâncias, se uniram. Aqui, o narrador, ou seja, a mulher que me escreve, é personagem da personagem. Minha personagem. [...] ela é ela, eu sou eu. Quanto à autora, não sei quem é. Não entra na estória (71-72).

Por toda la novela, la protagonista trata de mantener separadas a las tres figuras, pero no se puede. Los límites se borran; las identidades individuales se vuelven difusas. El discurso de la novela siempre es dialógico; tan pronto como la protagonista afirma una cosa absoluta (la autora no entra en la historia), la cuestiona: "Ou entra? Seremos projeções dos seus fantasmas?" (72). No hay ninguna verdad absoluta aquí; todo se contradice. Parente Cunha emplea un vocabulario de contradicción a través de toda la novela: "Eu me acho, quando ela sabe que me perdeu. Não, não é um jogo. É uma luta" (20); "Ela não sabe que me ama no seu ódio. Ao me negar, ela me afirma de corpo inteiro" (49). La protagonista y "a mulher que me escreve" viven sus propias contradicciones, sus propias negaciones.

Otra vez en As dozes cores do vermelho (1988), Parente Cunha nos muestra un sujeto múltiple, contradictorio, constituido en género sexual, pero también en clase y raza. La multiplicidad se nota inmediatamente en la forma como la novela está escrita en tres columnas - eu: una primera persona que recuerda sucesos y descubrimientos pasados; você: una segunda persona que dialoga acerca de varias preocupaciones en el presente; y ela: una tercera persona que narra aventuras futuras. ${ }^{5}$ El formato columnario nos obliga a confrontarnos, como lectores, de manera visual, con la sujetividad múltiple de la protagonista. No podemos leer las tres secciones a la vez. Miramos primero a la izquierda, luego al centro, después a la derecha, estudiando cada reflejo como un cliente probándose ropa frente a los múltiples espejos de una tienda. Al mirar el texto de As does cores do vertello, es como si viéramos los reflejos múltiples de la protagonista en los espejos de Mulher no espelho. En una maniobra como la de

\footnotetext{
${ }^{5}$ Aunque La muerte de Artemio Cruz también se narra en las tres voces (primera, segunda y tercera persona), en la novela mexicana las tres voces no están presentadas al mismo tiempo en cada página.
} 
"Las Meninas", los lectores de As does cores do vertello se encuentran ocupando el espacio físico de la protagonista de Mulher no espelho.

La relación dialógica entre las columnas demuestra los elementos activos, relacionales, heterogéneos, no idénticos del dialogismo que Bakhtin define como característica de la novela como género. En el ensayo de Julia Kristeva sobre las teorías de Bakhtin, "Word, Dialogue, and Novel", ella explora la ambivalencia de comunicación entre la "representación por el lenguaje" y la "experiencia en el lenguaje" (85 traducción mía). As doze cores do vertello emplea efectos textuales como el formato columnario para llenar los vacíos del sentido textual. La novela de Parente Cunha confirma la aserción de Drucilla Cornell y Adam Thurschwell que "[u]ltimately, the 'truth' of nonidentity can only be shown, not told" (160).

En su prólogo, "Antes de atravessar o arco-íris", Parente Cunha elucida su estrategia narrativa:

Ao mesmo tempo em que cada coluna se relaciona indissoluvelmente com o todo, possui também vida própria e independente. Fragmentos e totalidade, instantâneos e fluxos de vida. Existir é juntar pedaços que permanecem e coexistem em dimensão una e múltipla (9).

Existir es juntar los pedazos - cada persona está constituida de muchas partes. Este prefacio de As doze cores do vertello reitera las afirmaciones de la protagonista en Mulher no Espelho que cada persona tiene muchas voces, muchos lados, muchos silencios.

En As doze cores do vertello la protagonista es otra mujer sin nombre, sin identidad estable y unificada, cuya sujetividad sólo se puede entender en las intersecciones, los silencios, las diferencias y las variaciones. Ella encarna los papeles conflictivos y constreñidos de niña, adulta, amiga, esposa, madre, amante, artista. Fragmentada por estas afiliaciones físicas, sociales y psicológicas con otras personas, no le queda una identidad unificada.

Como las tres figuras femeninas de escritora en Mulher no espelho, vemos que en As doze cores do vertello la mujer está representada como artista. Ambas novelas ligan la creatividad y la búsqueda de alguna forma (aunque sea provisional) de la autorealización. Porque en cada novela, el espacio creativo es un espacio alternativo donde la mujer puede crear su propia realidad, una realidad que no tiene que conformarse con las normas de lo que debe ser una mujer, normas que son "culturally mandated, internally policed and hegemonically poised" (DuPlessis 5).

Ninguna de las mujeres se siente cómoda en el papel restringido de mujer burguesa. En Mulher no Espelho, la protagonista descubre la carga que puede ser el cuerpo femenino: "Presa no meu próprio peso, quero andar e não posso" (13). Esta protagonista no puede andar bien porque tiene los pies comidos por las ratas. Como las mujeres chinas tradicionales con los pies atados, tiene una mobilidad limitada. De manera similar, la protagonista de $A$ s doze cores do vertello descubre que la condición femenina conlleva muchas reglas de lo que se puede y de lo que no se puede hacer: 
Eu devia comportar-me e ter juízo e falar baixo e rir pouco e não gesticular e não mudar a roupa na vista dos outros. Não não ão ã. Sutiã. Já ia começar a usar sutiã para não deixar o peito solto debaixo da combinação.[...] Eu não devia ficar fazendo perguntas. Não devia ficar conversando com os meninos. Aprendia a costurar a bordar a cozinhar eu aprendia a ser uma boa dona-de-casa (14).

Vemos los mismos patrones sociales en As doze cores do vertello que aparecen en Mulher no Espelho: la chica no debe tener mucho contacto con varones, debe prepararse para ser buena ama de casa y no debe hacer tantas preguntas.

En las columnas de la izquierda en As doze cozes do vertello, vemos a la protagonista en la escuela, con "quarto caixas de lápis de cor" (12), queriendo ser pintora, pero con ideas artísticas demasiado rebeldes según la maestra. Cuando la protagonista pinta un cielo verde, la profesora le dice que el cielo debe ser azul. Al pensar en qué color sería la risa en vez de prestar atención durante la clase de matemáticas, ella tiene que "copiar a tabuada de 9 nove vezes nove" (12). Su rebeldía no se limita a las ideas artísticas sino que le incita a hacer preguntas indelicadas, preguntas que tienen que ver con la raza, la clase y la sexualidad:

Por que desonrada? Como se perde a honra? Onde é o mau passo? O que é fazer mal? Por que mulher de vida? Por que é feio? [...] Por que não podia ser amiga da menina dos cabelos cor de fogo? Por que mau exemplo? [...] Por que estado interessante? [...] O que acontece na noite do casamento? Por que é coisa feia? (32).

Tiene conciencia del prejuicio contra la chica pelirroja (hija de prostituta) y la chica negra (de clase pobre) y muchas veces se alía con ellas.

En las columnas centrales, la protagonista está casada con un marido rígido, identificado siempre con su "pasta preta", un marido que se queja de que ella malgaste su tiempo con pinturas que nadie entiende en vez de cuidar mejor a las hijas. Entre los quehaceres domésticos y su trabajo asalariado, no tiene tiempo para pintar. Tampoco tiene completa libertad para escoger a sus amigas, porque "seu marido não gosta de gente negra" (27). Las amigas del colegio siguen siendo amigas de ella a pesar de la desaprobación del marido rígido, que ni le permite entrar a la mujer negra. ${ }^{6}$ Como la protagonista de Mulher no espelho y como Alicia frente el espejo, siempre quiere saber "O que há do lado de lá?" (45).

En la columna de la derecha, está el sueño: “Ela viajará irá e verá e fará ver as formas informes e o céu vermelhos e as cores das cores e riso mais grito" (37). En esta columna va desde el miedo de tener una exposición de su arte y el tirar unos cuadros cuando el marido le dice que no hay espacio para estas pinturas que nadie entiende hasta ganar dinero de sus cuadros, comprar el apartamento más grande que el marido nunca

\footnotetext{
6 "A campainha tocando.[...] Seu marido vai abrir a porta. Quem é? Ninguém. Foi engano. Sorvetinho. Cafezinho. Pela janela você vê lá embaixo sua amiga negra entrando no carro branco" (37).
} 
pudo comprar con su sueldo y recibir premios internacionales. Pero el éxito tiene su precio también.

En As doze cores do vertello, como en Mulher no espelho, Parente Cunha muestra el género sexual como construcción social, al explorar los patrones sociales de cómo debe ser la mujer, las dificultades con las cuales se enfrenta al tratar de salir de estos patrones y la imposibilidad de ser un sujeto unificado y unívoco bajo estas condiciones. La autora cuestiona el concepto de identidad cuando se emplea para encarcelar las partes diferentes y conflictivas de una persona. Así descentra el género autobiográfico y el género femenino. El sujeto femenino históricamente se produce como objeto por medio de las prácticas y los discursos de la femineidad tanto como el sujeto autobiográfico se constituye por medio de las prácticas y los discursos de la autobiografía. Parente Cunha emplea la ficción autobiográfica como un escenario en el cual experimenta con la reconstrucción de los discursos representativos e ideológicos que constituyen la sujetividad de las mujeres brasileñas. ${ }^{7}$ Se sirve de la autobiografía ficcional para mostrar cómo el acto auto-posicional de escribir pone en tela de juicio el "ser", cómo las identidades nunca pueden ser auto-idénticas, y cómo la autoridad también se complica cuando las formas heredadas del discurso literario se descartan en la creación de formas nuevas. Al capturar a la lectora en el juego de los espejos, al exigir la participación de la lectora en la construcción de la identidad de la protagonista, Parente Cunha refracciona la autoridad sobre la identidad desde la autora hasta la lectora y refleja en las superficies espejadas de sus estrategias textuales los mismos temas que explora en sus ficciones.

En la ficción de Parente Cunha, el sujeto que habla así reproduce en el sujeto que lee la experiencia de resquebrarse, la tensión generada por el estirarse entre la identificación y la otredad, entre lo idéntico y lo diferente. La brasileña emplea una forma de escribir deconstructiva que Toril Moi explica como "one that engages with and thereby exposes the duplicitous nature of discourse" (9). Así, sus estrategias narrativas reflejan su política. Para leer As Doze Cores do Vertello, los lectores tienen que aceptar la naturaleza fragmentada de la identidad de la protagonista. También tienen que decidir cómo van a leer el texto: por ejemplo, leer cada una de las tres columnas, doblar la página y leer las próximas tres columnas; o leer todas las columnas a la izquierda del texto, después todas las columnas centrales y luego todas las columnas a la derecha. En este sentido literal, la forma del texto les obliga a los lectores a participar en la construcción de la sujetividad de la protagonista.

Con las novelas de Luisa Futoransky, los lectores otra vez participan en la construcción de la sujetividad de la protagonista. En Son cuentos chinos (1983) y De Pe a Pa (1986), Futoransky escribe dos novelas que, como las de Parente Cunha,

\footnotetext{
${ }^{7}$ Gilmore discute este fenómeno en relación con las escritoras en Autobiographics (85). Ella afirma que el sujeto autobiográfico no es una unidad singular sino una red de diferencias dentro de la cual el sujeto está inscrito. Explica que el sujeto autobiográfico está distribuido entre el ser histórico y el ser textual, los dos siendo versiones del ser que escribe.
} 
residen en las fronteras entre los géneros de la ficción autobiográfica y la autobiografía ficcional. Al escribir en los márgenes de los géneros, Futoransky atestigua sobre las constricciones impuestas por las convenciones de género y busca una libertad fuera de las convenciones. Este escribir en los márgenes es una característica que comparten Parente Cunha y Futoransky.

La trama romántica tradicional del siglo XIX, como paradigma narrativo, restringe a la protagonista femenina, reprime cualquier deseo de su parte de independencia y emplea la incorporación de individuos en parejas heterosexuales para señalar su éxito personal y narrativo. Varias escritoras contemporáneas crean ficciones que niegan o reconstruyen estos paradigmas narrativos a veces seductores pero más que nada destructivos que han sido "culturally mandated, internally policed and hegemonically poised" (DuPlessis 5). Algunas de estas autoras quieren producir obras narrativas que incorporan, incluso celebran, a las mujeres que quedan fuera de la norma mítica de blanca, joven, delgada, guapa, cristiana y heterosexual. ${ }^{8}$ Al cuestionar la autoridad de los discursos literarios heredados, las escritoras también pueden desafiar los discursos dominantes que dictan los sistemas de valor, las instituciones y las estructuras de poder de sus sociedades.

Las dos novelas de Futoransky aquí discutidas comparten la misma protagonista, Laura Kaplansky, un sujeto consciente de cómo su sujetividad se constituye "in gender, to be sure, though not by sexual difference alone, but rather across languages and cultural representations; a subject en-gendered in the experience of race and class" (de Lauretis 2) y de cómo no cabe dentro de la norma mítica. Kaplansky es una mujer argentina que vive en el extranjero (en China en la primera novela y en París en la segunda), queriendo ser escritora y preguntándose “¿Puede haber en este mundo mayor desgracia que ser mujer, cuarentona, sola, nada flaca, judía, sudamericana y bastante voluble a las pasiones?". Su identidad está constituída por todo lo que es negativo en el sistema de valores de la sociedad. Es un nada impuesto desde afuera, por un mundo patriarcal de poder y de riqueza. Incómoda con su etnicidad e infeliz con su identidad, ella aspira a llegar a aceptar y a reformar esa identidad por medio de su escritura. EI proceso creativo de escribir se presenta en Son cuentos chinos como un camino posible hacia el auto-conocimiento y la auto-realización. Al admitir que todavía no acepta por completo su nombre ni su apariencia física, "obvio que-no-sé-qui-én-soy-ni-de-dónde-ven-go-ni-a-dón-de-voy," ella quiere escribir hasta que se purgue de "todos mis babosos demonios" (55). El escribir, entonces, será catártico.

En los textos de Futoransky se nota la fascinación por las maneras en que las sujetividades se constituyen "across languages and cultural representations" (de Lauretis 2). En Son cuentos chinos, recuenta la historia japonesa de la kuchisake-ona,

"La norma mítica es un término de Audre Lourde, quien la define como "white, thin. male. young, heterosexual, christian and financially secure." ("Age, Race, Class, and Sex: Women Redefining Difference" Out There (282). La he cambiado un poco para que describa las características de la heroína de una novela romántica tradicional. 
una mujer muy bella que se suicidó después de ser desfigurada en la cara. Se dice que ella anda vagando por los corredores de las escuelas primarias, preguntándoles a los niños, ¿Todavía soy linda? ¿Todavía soy linda? ¿Todavía soy linda?” (51). Aunque Futoranksy no hace explícita la conexión, la necesidad obsesiva de la kuchisake-ona de tener afirmada su belleza de manera verbal le obliga invocar a la reina del cuento Blanca Nieves y los Siete Enanitos, quien le pregunta todos los días al espejo mágico "Mirror, mirror on the wall, who's the fairest of them all?" Los subyacentes significados raciales y estéticos del cuento de hadas resuenan con los textos de Futoransky. El hecho de que iban a llevarle a Blanca Nieves al bosque y quitarle el corazón ilustra lo importante que es ser la más bonita de todas. El sentido dual de "fairest" - la más bonita pero también la más blanca- establece modelos con los cuales Laura Kaplansky no puede conformar. ${ }^{10}$

Kaplansky se refiere a Alice in Wonderland en su texto, al sugerir que ella también ha pasado por el espejo a otro mundo. El otro mundo de Kaplansky es un parque zoológico, donde todos los animales y sus costumbres son desconocidos para ella. "Lástima que en este zoo no pongan carteles: este animal muerde, este animal escupe. este animal es venenoso, y una tenga que andar por su cuenta y riesgo averiguándolo todo" (90). El hecho de que menciona un animal que escupe enfatiza su conexión entre la gente china y los animales exóticos, ya que ella se queja varias veces en el texto de la costumbre china de escupir en la calle. Después de sentirse ella como mono en el zoológico o delfín en el acuario (39), Kaplansky aquí da vuelta a la situación. Tales metáforas ejemplifican lo ajeno que son estas culturas a la vez que manifiestan la preocupación de Futoransky tanto con la impermeabilidad de las culturas como con la necesidad de traducirlas para poder sobrevivir en exilio.

Para Kaplansky, Pekín es una ciudad que "a veces [le] da náuseas" (21). Son cuentos chinos es la narración de una mujer que vive y trabaja en un país donde siempre se siente dislocada, incapaz de entender el lenguaje ni los códigos culturales de la gente a su alrededor. La mayor parte del texto se compone de comentarios del lenguaje, el comportamiento, los ritos, la ropa y las costumbres que ella observa en Pekín. Cita observaciones de sus colegas chinos y de fuentes budistas, confucianas, y del budismo Zen, esforzándose para expresar en español, y así entender, estos sentimientos y creencias diferentes. En ambos Son cuentos chinos y De pe a pa, Laura Kaplansky busca palabras en castellano para describir las realidades distintas que encuentra en Japón, China y Francia; mientras Luisa Futoransky se esfuerza para crear mundos alternativos "wherein individual human subjects could experience the autonomy denied them in their cultural world" (Pease 108). Al escoger una "heroína" improbable

\footnotetext{
"Se menciona el cuento de hadas en otro momento del texto: "Por primera vez desde la fundación de la República apareció un periódico en inglés: el China Daily. que como su nombre lo indica no es cotidiano y sí trisemanal.... El número tercero dedica toda una página al comentario de Blanca Nieves y los siete enanitos con una foto de la benemérita y los susodichos engendritos nombrados cada uno por sus respectivos apelativos" (97).

${ }^{10}$ Gilbert y Gubar discuten el cuento de Blanca Nieves en The Madwoman in the Attic (36-44).
} 
como la protagonista de sus primeras dos novelas, Futoranksy incita a sus lectores para que se definan en sus propios términos.

Kaplanksy nota su propia marginalización dentro de la comunidad de exiliados en Pekín. Por su nacionalidad, su etnicidad y su falta de recursos económicos, no forma parte de la primera categoría. Después de hablar de experiencias médicas en Pekín, advierte:

Los residentes de primera clase, más blanquitos digamos, que hasta en eso nos discriminan, tienen otro hospital, así que por eso no sé cómo sufren ni se tratan los resfríos la comunidad angloeuropea de Pekín (38).

Esta sujetividad constituida por raza y clase es la que la margina.

La exiliada Kaplansky nunca se escapa de sus recuerdos de Buenos Aires ni pierde su punto de vista argentino. Para Kaplansky, su país de origen "es una herida crónica, como fumar desde los quince. A los cuarenta y pico, difícil concebir el mundo sin la cortina de humo propia, sin la sonoridad de la propia tos" (De pe a pa 11). Su identidad argentina es el filtro a través del cual ella ve el mundo ya que las experiencias en otros países evocan recuerdos de, y comentarios sobre, experiencias anteriores en Buenos Aires. ${ }^{11}$ Sus narrativas de la vida en China y París se cuentan en un español coloquial porteño muchas veces acosado para explicar los términos y costumbres extraños que encuentra Kaplansky. La inclusión frecuente de términos en otras lenguas subraya la imposibilidad de expresar las experiencias transnacionales en una sola lengua nacional. ${ }^{12}$

Los textos de Futoransky subrayan la idea de la mujer como exiliada perpetua en un mundo patriarcal. ${ }^{13}$ Futoransky delinea el exilio como el camino tanto de su vida como de su profesión - "Ser mujer en nuestro medio [literario] es, en cierto modo, estar exiliado" (ponencia en la universidad de Johns Hopkins). Futoransky cree que "una mujer que no puede expresarse es una exiliada interior" (ponencia en Johns Hopkins). Al inventar un relato oral autobiográfico en las entrevistas y ponencias, ella ve el escribir y el exilio como partes integrales de su identidad: "No sé muy bien lo que es

\footnotetext{
"Sus recuerdos de sucesos pasados muchas veces le incitan a reflexionar en como han formado su identidad. La descripción de Friederike Mayröcker de su propio proceso de escribir parece ser aplicable a Futoransky también: "Para poner en marcha mi 'máquina de concienciación', aprieto el botón del recuerdo de algún punto en el pasado, haciendo sugerir con ello algo en el centro de mi conciencia con gran intensidad y con dinamismo propio; es estático, y a la vez funciona como punto de irradiación para múltiples posibilidades de asociación". Citada en Ciplijauskaité (24-25).

12 Por más en este sujeto, ver Schwartz, Capítulo 5.

${ }^{13}$ Shari Benstock afirma que para las mujeres, la definición del patriarcado "already assumes the reality of expatriate in patria" y que "this expatriation is internalized, experienced as an exclusion imposed from the outside and lived from the inside in such a way that the separation of outside from inside ... cannot be easily distinguished" (Women's Writing in Exile 20).
} 
el exilio, lo que es escribir, lo que es leer. Lo único que sé es que no puedo hacer otra cosa" (ponencia en Johns Hopkins). Para Luisa Futoransky, como para su protagonista ficcional Laura Kaplansky, vivir es escribir.

Los textos de Parente Cunha y Futoransky desafian los conceptos tradicionales de la identidad femenina al poner énfasis en su provisionalidad y posicionalidad, las maneras en que tanto el género sexual como la identidad son construidos en y por el lenguaje, y cómo el discurso funciona para producir conocimiento y poder. En sus obras metaficcionales, la protagonista tiene conciencia de que su sujetividad es mediada, provisional, que existe sólo en la escritura en sí. Las meditaciones metaficcionales de las protagonistas muestran cómo las fuerzas sociales y literarias que median esta sujetividad no son favorables a las mujeres. Al revelar la naturaleza arbitraria del lenguaje, los valores y las imágenes empleados históricamente para construir, deformar y clasificar lo femenino, estas autoras estimulan otras formas de ver lo femenino. Al crear protagonistas que muchas veces son escritoras, Parente Cunha y Futoransky demuestran cómo el escribir facilita la creación de un ser múltiple y contradictorio, engendrado en la experiencia de raza, clase, lengua, cultura y género sexual.

\section{Obras CITADAS}

Bakhtin, M. M. The Dialogic Imagination. Austin: University of Texas Press, 1981. Beard, Laura J. "The Mirrored Self: Helena Parente Cunha's Mulher no Espelho". College Literature, 22:1 (1995): 103-118.

Ciplijauskaité, Biruté. La novela femenina contemporánea. Barcelona: Anthropos, 1988.

Cornell, Drucilla \& Adam Thurschwell. "Feminism, Negativity, Intersubjectivity". Feminism as Critique: On the Politics of Gender. Seyla Benhabib and Drucilla Cornell, eds. Minneapolis: University of Minnesota Press, 1987.

DuPlessis, Rachel Blau. Writing Beyond the Ending. Bloomington: Indiana University Press, 1985.

Fuentes, Carlos. La muerte de Artemio Cruz. México: Fondo de Cultura Económica, 1962.

Futoransky, Luisa. Discurso no publicado en The Johns Hopkins University, Baltimore, MD. March 1993.

Urracas. Buenos Aires: Planeta, 1992.

Son cuentos chinos. Montevideo: Trilce, 1986.

De Pe a Pa (o de Pekín a París). Barcelona: Anagrama, 1986.

Gilmore, Leigh. Autobiographics: A Feminist Theory of Women's Self-Representation. Ithaca: Cornell University Press, 1994.

Kristeva, Julia. Desire in Language. New York: Columbia University Press, 1980. Lauretis, Teresa de. Technologies of Gender: Essays on Theory, Film, and Fiction. Bloomington: Indiana University Press, 1987. 
Moi, Toril. Sexual/textual Politics: Feminist Literary Theory. Routledge: London, 1988.

Parente Cunha, Helena. As Doze Cores do Vertello. Río de Janeiro: Editora UFRJ, 1988. Mulher no Espelho. São Paulo: Art Editora, 1985.

Pease, Donald. "Author". Critical Terms for Literary Study. Frank Lentricchia \& Thomas McLaughlin, eds. Chicago: University of Chicago Press, 1990.

Schwartz, Marcy E. "Writing Paris into Contemporary Latin American Narrative: The City as Intertext in Cortázar, Scorza, Bryce Echenique and Futoransky". Disertación de Doctorado. The Johns Hopkins University, 1992.

White, Patrick. The Twyborn Affair. London: Penguin, 1979. 
